\title{
CHAPTER 7 \\ Progress and Challenges of Infrastructure Spending in Timor-Leste
}

\author{
Antonio Vitor'
}

\section{Background}

Most basic infrastructure such as power, water, transport, telecommunications, office and school buildings built by Portuguese and Indonesian administrations in Timor-Leste were destroyed when the country was liberated in 1999.

\begin{abstract}
Almost everything needed to be rebuilt and the country faced a massive task in planning and executing a wholesale infrastructure investment program valued at more than US $\$ 10$ billion. Eleven years later, while notable progress had been made in some sectors, Timor-Leste remains far behind its original investment targets. While the country possesses significant oil \& gas resources to support infrastructure financing, its capacity for investment planning and implementation remain constrained (Darcy 2012: 1).
\end{abstract}

Prior to 2006, most public expenditure was funded by the international development community. However, with the creation of a dedicated Infrastructure Fund, Timor-Leste's own resources are now funding around 80 per cent of public expenditure. Operating within the framework provided by the Strategic Development Plan 2011-2030 (SDP), and the infrastructure

1 The views expressed in this chapter are those of the author's and do not necessarily reflect the views and
policies of ADB or its Board of Governors, the governments they represent, or the Government of Timor-Leste. 
program of the Fifth Constitutional Government 2012-2017, the government hopes to better direct and measure Timor-Leste's development performance in the infrastructure sector.

Owing to the inflow of funds from petroleum sales over the past few years, Timor-Leste's government has dramatically expanded the level of resources invested in infrastructure development. Since 2007, the budget of the Ministry of Infrastructure (including projects funded under the Infrastructure Fund) has increased by more than an order of magnitude to almost US\$200 million a year. In 2013, the country planned to spend about 15 per cent of its gross domestic product (GDP) on infrastructure development. This is an enormous figure by international standards, where developing countries spending 6 per cent of their GDP on infrastructure are generally considered to be making a more than adequate contribution to their infrastructure development needs. Capital expenditure requirements are higher in post-conflict environments, where challenges are often greater in terms of the availability of skilled labour and expertise. Even taking this into account, Timor-Leste's infrastructure expenditure targets are very ambitious.

However, the high and increasing budgetary allocations for infrastructure have added to the burden of implementing agencies, and while disbursement ratios have improved over recent years, the Ministry of Public Works (MPW) is still only able to disburse about two thirds of its budget. Large budgets, combined with the limited implementation capacity of the infrastructure ministries, lead to pressures to divert resources to pay for ad hoc 'emergency projects'. Examples of these projects include the well-known Pakote Referendum (Referendum Package), which totalled US\$70 million, for which funding was diverted from the National Electrification Project, and an emergency drainage project for which funding was diverted from a multi-year project for drainage.

The current extent and state of Timor-Leste's infrastructure requires substantial investment to meet the growing needs of the country. Therefore, proper prioritisation, effective and efficient implementation of selective infrastructure projects is crucial. Timor-Leste requires extensive and diverse infrastructure development, but in this chapter I limit discussion to issues of roads, electricity, water and sanitation, ports, and airport development.

\section{Targets in the Strategic Development Plan 2011-2030}

Timor-Leste's SDP sets an ambitious goal to achieve middle-income country status by 2030. This is a reachable goal if Timor-Leste can manage its resources properly and prudently to create a modern and productive economy. 
The status of infrastructure remains inadequate and inefficient with increasing development demands. Infrastructure spending should, therefore, be directed towards building and maintaining the core and productive infrastructure needed to support the growth of the nation, increase productivity, create jobs, and support the development of national private sector. In doing so, the scale and cost implications are large and ongoing (RDTL 2011: 70-72).

The relationship between infrastructure and economic development has been widely recognised. Empirical evidence demonstrates that shortfalls in infrastructure lead to declining productivity (Aschauer 1989a, 1989b, 1991). This relationship implies that public capital is an important input in the production function. Many targets set for infrastructure in the SDP should be seen in this context. Building Timor-Leste's infrastructure is not an easy task, particularly where demand for infrastructure is pressing while the cost of supply is enormously high. There are no simple answers, but the targets set for key infrastructure, while ambitious, are tough choices the country has to make to overcome the constraints in socioeconomic development. The design and planning for infrastructure investment are, therefore, key preconditions for social and economic development.

Does the SDP make the right choices for infrastructure spending to establish preconditions for state social services and to support economic growth? This question is hotly debated, but, in my view, the choice to invest in transport infrastructure such as ports, airports, roads and bridges is compelling. As Brooks has commented,

Asia benefits from market-driven integration, where large trade and FDI [foreign direct investment] flows respond to infrastructure development ... and efficient infrastructure services lower transaction costs, raise value-added and increase potential profitability for producers while increasing and expanding linkages to global supply chains and distribution networks (2009: 1).

Conversely, inadequate infrastructure can cost an economy significant unrealised gain from trade, and lead to an inability to transport goods and people efficiently, [while] an inadequate power supply to operate machines leads to microeconomic as well as macroeconomics bottlenecks ... infrastructure can also yield positive externalities' (Brooks 2008: 1).

The plan for road network development is to deliver a comprehensive road maintenance program, to rehabilitate all existing roads, to construct new bridges, and to provide all-weather access on major routes within five years (RDTL 2011: 75). In Timor-Leste, roads are categorised into national, district, rural, and urban. All national and district roads will be fully rehabilitated to an international standard by 2020. All rural roads are expected to be fully rehabilitated by 2015 . A bridge construction program to construct and rehabilitate bridges that are in 
need of replacement or repair will also be undertaken. There are around 3,200 linear metres of bridges throughout the nation. District roads have been the highest priority for repair. A national highway of two lanes in each direction capable of taking a full-length container at an average speed of $60 \mathrm{~km}$ per hour is planned to be built on the south coast, linking Suai in the western part and Beaco in the eastern part of the country. A ring road around the country has also been envisaged (RDTL 2011: 72-76). The SDP's comprehensive, 10-year roadbuilding program will give certainty and ongoing opportunities to international and national road construction companies to encourage such business to invest and grow in Timor-Leste. This will improve Timor-Leste's private-sector development and create jobs throughout the nation (RDTL 2011: 72).

The plan for water and sanitation is to overcome the many challenges involved in providing improved access to clean water and sanitation across Timor-Leste. This includes the construction of a major sewerage collection system in Dili, providing a safe, 24-hour, piped water supply to households in 12 district centres, and installing water systems and community latrines in rural areas. The SDP sets a target that by 2030 all citizens of Timor-Leste will have access to clean water and improved sanitation. The target for urban districts is to provide 60 per cent access to appropriate, improved sanitation facilities by 2015. Alongside sanitation facilities, the SDP also sets out to rehabilitate existing sewers, and separate sewage from stormwater drainage by building intercepting sewers, installing pilot toilet facilities in households and facilitating local treatment of sewerage. These initiatives include building appropriate treatment facilities in a staged way-connecting commercial properties first, then residential septic tank effluent, followed by all houses that have flush toilets. Other options include building a trunk sewer along the waterfront to take effluent from the intercepting sewers. The expectation is that by 2020 there will be appropriate, well-operated and maintained, sustainable infrastructure for the collection, treatment and disposal of sewage in Dili (RDTL 2011: 77-81). While this is an achievable goal, the works must be outsourced, and a proper, operational and detailed infrastructure plan put in place.

'Electricity is seen as a basic right and the foundation for our economic future.' According to the SDP, by 2015 everyone in Timor-Leste will have access to reliable electricity for 24 hours a day. To achieve this, the government has commenced investment in new power plants, substations and transmission lines, as well as distribution systems. An expansion of renewable energy systems is also envisaged in the SDP. The establishment of two power plants for electricity generation, and the roll-out of most transmission and distribution systems have been accomplished. Apart from the national electricity grid, the government has also rolled out a rural electrification program aimed at improving the 
living conditions of the majority of the population, including more remote communities. The SDP states that by 2020 at least half of Timor-Leste energy needs will be met from renewable energy sources (RDTL 2011: 85-92).

The international airport in Dili will be extended and a new terminal will be built. Rehabilitation of building airstrips for at least Suai, Oecusse/Ambeno, Lospalos, Maliana, Viqueque, Atauro and Same are being considered. While the plan for Baucau airport is for it to be an alternative airport to Dili, it will be also used as aero-military base (RDTL 2011: 97-98).

Two new seaports - one at Tibar near Dili and another in Suai-are envisaged. Construction of these two ports is expected to support the growing economy and meet future industry and freight demands (RDTL 2011: 94). The plan for Tibar port includes the construction of a wharf and onshore facilities, a new road from Dili to Tibar, dredging, and possible construction of a breakwater. These facilities will be built in phases in accordance with growing demand and funding availability. The Tibar Port Project has already commenced, and by 2020 Timor-Leste is expected to have a new, fully operational and efficient major port. A logistics supply base for the petroleum sector will be established in Suai. This is expected to provide capacity for the south coast to develop a domestic petroleum sector along with related and supporting industries and businesses. The expectation is that when this port facility is in place it will attract investment and promote growth, and provide an international access point to Timor-Leste. Alongside these two major ports, regional ports construction will be undertaken over the next 10 years. Port facilities will be built, repaired or substantially expanded (RDTL 2011: 93-96).

\section{What is the progress to date?}

Timor-Leste has an extensive system of national, district and rural roads that provide access to the rural parts of our nation where the majority of the population lives. The network is generally constructed to the Indonesian pavement standard of 4.5 metres width with lined masonry drains and two lane steel truss bridges. The Timor-Leste road network comprises national roads that link districts to each other, district roads that link district centres with sub-districts and rural roads that provide access to villages and the more remote areas. There are around $1,426 \mathrm{~km}$ of national roads, $869 \mathrm{~km}$ of district roads and 3,025 km of rural roads (RDTL 2011: 70).

The roads network development program is currently undergoing a significant expansion. Remarkable progress is being made on the national roads upgrade. According to the SDP, all national and district roads are to be fully rehabilitated to an international standard by 2020. All national roads will be upgraded to 
a width of 6 metres plus a 1-metre shoulder on both sides, and will include drainage and slope protection works. From 2011, the Government of TimorLeste and development partners - namely the Asian Development Bank (ADB), the Japan International Cooperation Agency (JICA), and the World Bank-are co-financing this national roads network development program. The agreement is to upgrade about 600 kilometres out of approximately 1,426 kilometres of the existing national roads by 2017. Percentage-wise, the government's program is securing about 40 per cent of the total length of Timor-Leste's national roads to be upgraded by 2017. Recently, the government and the ADB co-financed the upgrading of about 14 kilometres of LiquiçaMaubara section. This section is part of the main road link between the Nusa Tenggara Timur Province of Indonesia and Dili was due to be completed by December 2013. The civil work contracts for the upgrading of Dili-Liquiça and Tibar-Gleno road sections were awarded earlier in 2014 and works have recently commenced. Heavy maintenance for the section from Batugade to Maliana has been ongoing since 2012 .

In 2012, the government and JICA signed a loan agreement to upgrade the Dili-Manatuto-Baucau road link. The following year the design was completed and put out to tender, and the construction of the Dili to Manatuto road was scheduled to commence in 2014, with the remaining section from Manatuto to Baucau to be completed by 2017. Subsequently, the government and the World Bank signed a loan agreement to upgrade the Dili-Ainaro road link. Works were scheduled to commence in 2014 with a completion schedule by 2017. The government has also signed with ADB a new loan to finance the construction of the Manatuto-Natarbora road link, including the design for the upgrading of the Baucau-Lospalos road, the Lautem-Com road link and the Baucau-Viqueque road. This project was also scheduled to commence in 2014 and be completed by 2017.

Notable progress has also been made on rural road construction and rehabilitation. The government, in partnership with AusAID and the International Labour Organization (ILO), has rehabilitated 90 kilometres of roadway, while an additional 150 kilometres is scheduled to be rehabilitated by the second half of 2013. ${ }^{2}$ Despite the fact that rural road rehabilitation has achieved just 240 kilometres out of a total of 3,025 kilometres, to some extent this has been critically important as:

2 de Sousa, Gastão 9/8/2013. Progress Made during the First Year of the V-Government. Presentation at the Retreat of V-Government, Dili. 
over $70 \%$ of the population of Timor-Leste are living in rural areas and therefore any progress made will contribute to connect people and communities, encourage agricultural and natural resource development, increase rural incomes and allow for the effective delivery of government services including health care, education and security (RDTL 2011: 70).

Despite the highest priority being given to district roads, this category is recorded as receiving only limited attention, as by August 2013 there were just 70 kilometres maintained. A number of projects for district road rehabilitation are proceeding, but it has been difficult to track progress due to the absence of a reliable data. Most of these works have been undertaken on an ad hoc basis, with improper preparation, and poor adherence to the design and processing requirements necessary to ensure that resources expended will result in the anticipated benefits.

Water supply infrastructure is still recorded as lagging behind. The UN, the new government and its development partners have invested well over US $\$ 250$ million in the Dili water supply system since 2000. Investments have focused on emergency repairs, operational capacity-building and major infrastructure. Water sources, treatment plants and transmission mains are now in generally good condition, and have sufficient capacity to meet Dili's needs for several years (ADB 2007). An ongoing project for increased water supply for Dili is now progressing well. The project is covering three sub-zones within three different zones, supplying continuous potable water for about 1,600 households/ consumers. Works in two additional zones covering about 1,700 households are scheduled to commence in 2014. The Direcção Nacional de Água e Saneamento (DNSA; National Directorate for Water and Sanitation) has reintroduced water billing in Dili, particularly within the zones covered by the water supply project co-financed with the ADB. Another government project for Pante Makassar in Oecussi and Manatuto township is now at the procurement stage and is scheduled to commence construction in 2014. A further co-financed project with the ADB to implement the urban water supply is planned in accordance with the SDP.

A public-private partnership (PPP) pre-feasibility study was completed this year reviewing the tariff structure to ensure affordability for the urban poor and effective coverage of operational costs. It also assessed a realistic target date to meet the government's planned level of service expectations and commitments of matching funding. A full feasibility study will be conducted to assess the merits and risks of a PPP before commencing any tender process (Evans \& Peck 2013). 
There has been some good progress made in rural water and sanitation. One of the key players in this sector is the Be'e Saneamentu no Ijiene iha Komunidade or BESIK program (Rural Water Supply and Sanitation Program), financed by AusAID. This program covers all 13 districts and provides access to clean water for over 80 remote villages in Timor-Leste.

Very significant progress has been made in electricity supply. Despite the large investment and achievements made by the recent two periods of government, electricity infrastructure continues to attract conflicting opinions. By June 2013, the government had:

- completed two new power plants with 250-megawatt capacity and nine substations

- connected 506 kilometres of transmission lines out of a planned total of 603 kilometres

- provided 106,072 households with access to electricity; 97,072 households were connected to the grid

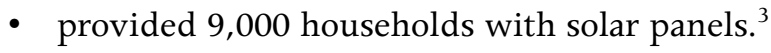

Timor-Leste is heavily dependent on a single national port in Dili for all general cargo imports and exports. The Port of Dili is struggling to cope with the volume of cargo and this situation is likely to worsen as the economy expands. Its limited capacity already results in a berthing backlog of between three and eight ships. To overcome this problem, a new multi-purpose port with a capacity of one million tonnes per year, and catering for commercial cargo and passenger needs will be constructed in Tibar, a few kilometres west of Dili (RDTL 2011: 93-94). The project has reached procurement stage and it will be implemented through a PPP.

\section{The challenges in delivering infrastructures in Timor-Leste}

The SDP places state-led capital spending at the centre of its development strategy. To deliver infrastructure as targeted in the SDP would be extremely challenging should there be no change in the current system, procurement practices and institutional arrangements. Timor-Leste lacks capacity both in terms of human resources as well as institutions to deliver SDP targets.

\footnotetext{
3 de Sousa, Gastão 2013. Minister of Public Works presentation at the Timor-Leste Development Partners meeting, Dili, 18-20 June.
} 
The national private sector, particularly in relation to construction, design and supervision, remains low and underdeveloped. The infrastructure to support the development of physical infrastructures needed by the country is limited.

State-led investment in infrastructure development requires the government to perform well in public investment management and public finance management. But this expectation is frequently not met given the continuing capacity constraints.

In addition to limited public sector capacities and capabilities to deliver infrastructure, there are natural impediments for private sector involvement. Timor-Leste can be categorised as a relatively small market for private investment. Its remoteness can result in high costs for doing business. A number of structural factors also constrain private sector investment. These include the weak macroeconomic environment, poor governance, extensive state involvement coupled with weak regulation, underdeveloped financial markets, the poor legal and investment policy environment and sensitivity about instability. These combined factors have led to low returns on capital and need to be addressed to establish a reliable and conducive investment environment.

In the absence of private sector in investment, the government has almost no other choice but to stimulate investment directly. The National Electrification Project, the Tasi Mane Project, the Tibar Port Project and the National Road Network Development are major to mega projects selected within the framework to generate future investment while providing basic infrastructure and services. Developing this concept led to an environment in which political economy influences investment logics.

The institutional arrangement for delivering infrastructure is also an issue. Over recent years, the government has established the Secretariado dos Grandes Projetos (Major Project Secretariat), the Agência de Desenvolvimento Nacional (National Development Agency) and the Comissão Nacional de Aprovisionamento (National Procurement Commission) to improve the efficiency and effectiveness of infrastructure planning and delivery. The objective behind the establishment of these agencies is to improve the way in which agencies responsible for planning and implementation can work together to ensure that projects are aligned with SDP objectives, are economically and financially viable, are delivered on time and on budget, and are sustained by the implementation of adequate operation and maintenance arrangements. However, there are overlapping responsibilities between some agencies involved in the infrastructure planning and delivery processes, and there remains a risk that resources are not being used optimally to deliver infrastructure against the objectives set out in the SDP. The current system for prioritising investments is not working effectively, and risks wasting government resources on inappropriate or poorly designed investments. 
Two key ministries responsible for implementing infrastructures are the MPW and the Ministry of Transport and Communications; however, with the creation of supporting agencies in the infrastructure sector, these government agencies have, to some extent, overlapping functions. For example, the MPW operates in an external environment of change, political uncertainty and political interference, and with multiple, changing and competing stakeholders.

What is currently lacking in most areas are sector or sub-sector strategies and plans. These would provide an intermediate step between the overall socioeconomic goal and strategy set out in the SDP, and detailed lists of proposed project interventions or macro-level targets. Such strategies and plans would provide:

1. a more fine-grained framework for sector and sub-sector development

2. a set of intermediate goals and sector or sub-sector development indicators that would allow planning and implementing agencies to better measure how individual project interventions are contributing to the realisation of overall sub-sector and sector outcomes.

Realising these objectives will, in turn, contribute to the realisation of the SDP's strategic socioeconomic goals.

The global experience of infrastructure development is that the achievement of efficient investment depends on a number of factors relating to the executing and implementing institutions and their relationships with each other, including clear plans and strategies. ${ }^{4}$ Many of these conditions are absent in Timor-Leste, and focusing on some of these areas could be helpful in improving the quality and efficiency of the country's infrastructure investment. Following are some of the most important preconditions for cost-effective and efficient infrastructure investment.

1. Close co-operation is required between all ministries and parastatal agencies involved with infrastructure.

2. There should be a clear separation of political and technical responsibilities. With policymakers setting aspirations and sector priorities, goals and targets, and technicians taking responsibility for deciding how to reach these goals, including determining whether to take in-house responsibility or to execute and evaluate, with delivery delegated to others under contract. Timor-Leste still has major issues in this area with frequent political interference in project selection and delivery.

4 Dobbs, R. et al. 2013. Infrastructure Productivity: How to Save \$1 Trillion a Year. London: McKinsey Global Institute. 
3. The government should engage the private sector where it can provide greatest value-including welcoming unsolicited proposals where appropriate. In reality, Timor-Leste is only at the first stage in this process, but understanding what capacity there is in the private sector to take on infrastructure and service delivery roles is an important step.

4. Trust-based stakeholder engagement should be supported by the development of transparent systems and provision of education (including to beneficiaries and stakeholders). This objective includes broad participation in the process, and compensation (or offsets) for those experiencing negative impacts. Again, Timor-Leste is at an early stage in this process, and gaining public trust is the first step.

5. Decisions on investment should be made based on robust and reliable information; this is crucial for sector and sub-sector strategies. Balance-sheet accounting on investments should be made public - to show spending and to promote equity. (Some progress is being made on this with the government's transparency portals in areas such as budget, procurement, expenditure and results.)

6. There should be adequate investment to obtain the required skills - building strong capabilities across the infrastructure value-chain. This goal also highlights the value of focused delivery units-hand-picked teams with a single objective to realise major investments.

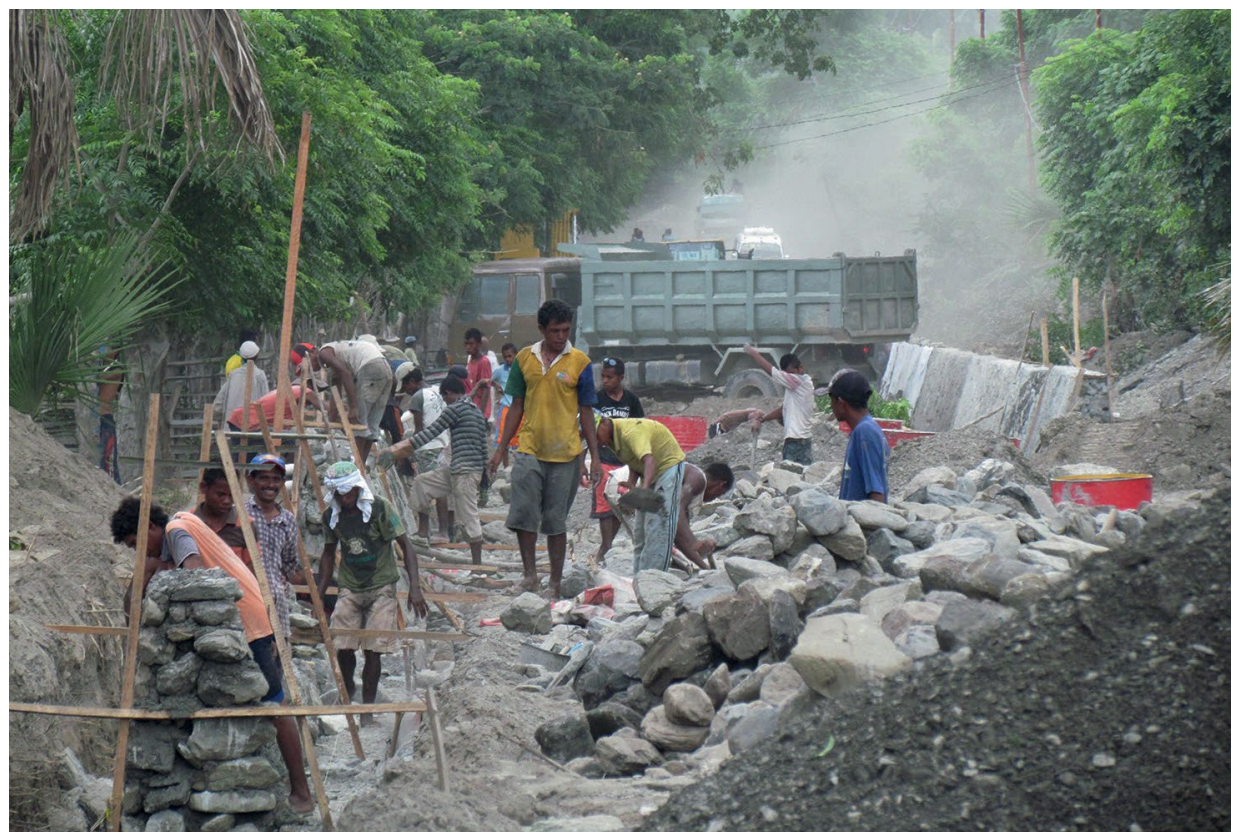

Figure 7.1 National road upgrading project.

Source: Antonio Vitor. 


\section{Conclusion}

Timor-Leste's infrastructure is inadequate and inefficient. The infrastructure built prior to 1999-2000 is deteriorating due in part to age, but largely due to lack of proper maintenance and rehabilitation over the previous decade and more. Most of the key infrastructure, such as ports, airports, major road networks and telecommunications, needs to be upgraded to suit the current and growing demands. There are conflicting views, however, around the selection priorities of infrastructure, given the widespread demand for improvements, and competing economic and political interests. Despite significant investment made so far, the results are yet to meet expectations. To date, the choice has been to invest in transport, telecommunication and the power sectors in order to meet basic infrastructure needs and establish a firm basis for socioeconomic development.

The challenges remain significant. The achievement of efficient infrastructure investment depends upon a number of factors that require effective co-ordination and planning, and the improved capacity of implementing agencies to fulfil their responsibilities and strategic plans.

\section{References}

Arthur, J. 2013. Timor-Leste: Review of ADB Capacity Building Support to Infrastructure Sector. Dili: Asian Development Bank.

Aschauer, D.A. 1989a. Is Public Expenditure Productive? Journal of Monetary Economics 23(March):177-200.

Aschauer, D.A. 1989b. Public Investment and Productivity Growth in the Group of Seven. Economics Perspective 13(September/October):17-25.

Aschauer, D.A. 1991. Infrastructure: America's Third Deficit. Challenge 34(March-April):39-45.

Brooks, D.H. 2008. Infrastructure and Trade in Asia: An Overview. In D.H. Menon (ed.). Infrastructure and Trade in Asia. Cheltenham: Asian Development Bank Institute and Edward Elgar Publishing, 1-14.

Brooks, D.H. 2009. Infrastructure's Role in Lowering Asia's Trade Costs. In D.H. Brooks and D. Hummels (eds). Infrastructure's Role in Lowering Asia's Trade Costs. Cheltenham: Asian Development Bank Institute and Edward Elgar Publishing, 1-16. 
Darcy, L. 2012. Implementing PPPS in Timor Leste: Institutional Challenges in the Near North. Public Infrastructure Bulletin 1(8):1-4.

Evans \& Peck 2013. Dili Water Supply Public Private Partnership Pre-Feasibility Assessment. Dili: ADB.

RDTL (República Democrática de Timor-Leste) 2011. Timor-Leste Strategic Development Plan 2011-2030. Dili: RDTL. 
This text is taken from A New Era? Timor-Leste after the UN, edited by Sue Ingram, Lia Kent and Andrew McWilliam, published 2015 by ANU Press, The Australian National University, Canberra, Australia. 